\title{
INCREASING PREVALENCE OF HEPATITIS AMONG TRANSFUSION TRANSMITTED INFECTIONS: A TERTIARY CARE CENTRE EXPERIENCE
}

Rupinder Kaur, Anuradha Singh, Gian Paul Singh

1. Associate Professor, Department of Pathology, Christian Medical College \& Hospital, Ludhiyana, Punjab.

2. Junior Lab Technician, Blood Transfusion Unit, Department of Pathology, Christian Medical College \& Hospital, Ludhiyana, Punjab.

3. Technical Supervisor, Blood Transfusion Unit, Department of Pathology, Christian Medical College \& Hospital, Ludhiyana, Punjab.

\section{CORRESPONDING AUTHOR}

Dr. Rupinder Kaur, MD

Associate Professor, Pathology \&

In charge Blood Transfusion Unit

Christian Medical College \& Hospital Brown Road,

Ludhiana- 141 008, Punjab, India

E-mail: rupicmc@yahoo.com,

Ph: 00919888499289

\begin{abstract}
Increasing Prevalence of Hepatitis among Transfusion Transmitted Infections: A tertiary care centre experience. BACKGROUND: Blood transfusion despite being a lifesaving intervention may result in acute or delayed complications and carries the risk of transfusiontransmissible infections (TTI's). There has been an alarming rise of hepatitis (B\&C) infection among blood donors and not much related to prevention or prophylaxis has been done so as to reduce the risk of transmission. AIMS OF THE STUDY: The study was done to find out the prevalence of Hepatitis B and Hepatitis $\mathrm{C}$ among transfusion transmitted infections in a healthy blood donor population METHODOLOGY: A six years retrospective study of sero-reactive cases of TTD's among the blood donors was done (2004-2009) in Blood Transfusion Unit, Christian Medical College \& Hospital, Ludhiana. The data was retrieved from the blood bank records with special emphasis on hepatitis infection among the blood donors. RESULTS: Over all 64,528 donors were screened for the Transfusion Transmitted infections (HBV, HCV, HIV1\&2,Malarial Parasite, and VDRL) of which majority were males. Overall seroprevelance for the transfusion transmitted infections was $2.72 \%$. Seropositivity for Hepatitis per se was $2.4 \%$. Majority of the donors were reactive for HCV infection (1.4\%) followed by HBV (1.0\%), HIV1\&2(0.2\%), VDRL $(0.1 \%)$ and Malaria parasite infection $(0.02 \%)$. CONCLUSION: There has been an alarming rise of hepatitis cases, especially HCV among the blood donor population which need to be looked upon and special preventive measures need to be taken at the national level to combat this problem.
\end{abstract}

KEY WORDS: Blood donors, Transfusion-transmitted infections, hepatitis

INTRODUCTION: Transfusion of blood and blood products is a life saving measure and saves millions of lives each year globally, but at the same time it also carries a significant risk of transmission of many blood transfusion transmitted infections (TTI's). Despite stringent donor screening and testing practices, safe blood free from transfusion-transmitted infections (TTI's) continues to be a threat to safe transfusion practices. ${ }^{1}$

Journal of Evolution of Medical and Dental Sciences/Volume1/Issue5/November-2012Page-875 
TTI's can exist as asymptomatic diseases (silent killers) in the hosts, and acquisition of infections during the window period from such blood donors can be a serious threat to the safety of the collected donations. ${ }^{2}$

Among the various TTI's, the most dreaded and less sought after infection is by Hepatitis B (HBV) and Hepatitis C (HCV) viruses and are considered two established causes of post transfusion hepatitis. Many Blood donors are carriers, not realizing that are infected with this disease. Individuals with chronic infection have a high risk of developing liver cirrhosis and hepatocellular carcinoma leading to serious mortality and morbidity. ${ }^{3}$ There are about 5.7 million cases of HIV in India, second highest pool of patients in the world. Syphilis is less often transmitted by blood and the prevalence is low in most studies reported. 4

We did this study to find the prevalence of TTI's with emphasis on hepatitis infection among blood donors in our hospital.

MATERIAL \& METHODS: This six years retrospective study was done in the Transfusion Medicine Unit, Christian Medical College \& Hospital, Ludhiana, a tertiary care centre in North India over a period of 6 years from 2004-2009. Average donor numbers is about 10,000-12,000 per year.

The donor's details were noted down from the donor consent forms kept in the blood bank records. The donor blood samples were later screened for mandatory tests [Malaria, Venereal Disease and Research Laboratory (V.D.R.L), Hepatitis B antigen (HBsAg), Anti HCV \& Anti HIV 1\&2)].

Testing for malaria parasite was done by card test based on malarial (pLDH) antigen based principle. VDRL testing was based on TPHA (Treponema Palladium Haemagglutination Antibody) based principle. Testing for Hepatitis B, Hepatitis C and HIV $1 \& 2$ were based on $3^{\text {rd }}$ generation ELISA techniques (Ortho Clinical Diagnostics, Vitros ECiQ-based on chemiluminiscense technology). The serological results were retrieved from the records available in the department

RESULT AND ANALYSIS: A total of 64,528 donors were screened over the 6 year study period. Majority (94.7\%) of them were replacement donors. Male donors (97.8\%) outnumbered females $(2.2 \%)$. Out of the potential donors screened, 1755 (2.72\%) of the blood donors were reactive for various Transfusion Transmitted Diseases (TTD's). The details are shown in Fig 1. Majority (71.8\%) of the donor's positive for TTD's (HBsAg, HCV and HIV) were in 18-35 years age group (Fig 2).

Prevalence of hepatitis infection formed the majority (2.4\%) of the total TTI's over the 6 year period ( Fig 3) of which HCV reactive donors were (1.4\%) and HBsAg were $1 \%$.Prevalence of HIV, VDRL, and MP was $0.2 \% .0 .1 \%$ and .02\% respectively. Hepatitis infection formed majority both among males and females. The detail regarding various TTI's among males and females are given in Table 1.

Co-infection was seen in $1.2 \%$ of the total TTD positive donors of which 14 donors had both HBsAg and HCV positivity. The detail is given in Table- 2

DISCUSSION: Blood transfusion even though is a lifesaving procedure is associated with acute and delayed complications and carries the risk of transmitting TTI's. Despite stringent donor screening and testing practices, safe blood free from transfusion-transmitted infections (TTI's) remains an elusive goal. ${ }^{1}$ Although technological advancements have led to the development of 
more sensitive methods to detect markers of TTI's, the problems of 'window period', falsenegative results, prevalence of asymptomatic carriers, genetic variability in viral strains and technical errors remain. ${ }^{5}$

Among the various TTI's, hepatitis has become an issue of global importance. Hepatitis B and $C$ are highly infectious and pose major public health problem in developing countries and are the commonest cause of chronic liver disease in several regions of the world. ${ }^{2}$ Hepatitis B is one of the most common diseases transmitted by blood and has infected two million people worldwide including an estimated 400 million chronically infected cases. Individuals with chronic infection have a high risk of developing liver cirrhosis and hepatocellular carcinoma. 6 Hepatitis $\mathrm{C}$ virus (HCV) infection is another common chronic blood born infection with an estimated 3.9 million persons infected by the virus and a high rate of development of liver cirrhosis. Infection by HBV and HCV causes serious mortality and morbidity. ${ }^{7}$

The present study showed higher seroprevelance of HBV and HCV among the blood donors as compared to other TTI's, rather it formed the majority of the infections

( $2.4 \%$ of the total $2.7 \%$ of reactive TTI's).

The prevalence of HBV reactive blood donors is different in various countries. It is as low as $0.1-0.5 \%$ in a healthy population in United States and Western Europe, whereas it ranges from $5-20 \%$ in far Eastern and some Tropical countries. ${ }^{8}$ Seroprevelance of HBsAg in various Indian studies has shown to range between $1.86 \%-4 \% \quad 9,10,11$, which was comparable to our study showing the incidence of HBsAg to be $1 \%$.

$\mathrm{HCV}$ is transmitted primarily through blood exposure. In contrast to HBV, about 20 to $40 \%$ of HCV cases are acute and majority of them progress to chronic infection. The long term risk of developing cirrhosis and hepatocellular carcinoma is greater in HCV infected individuals than in those infected with HBV. ${ }^{12}$ There is wide variation globally in the seroprevelance of HCV with the studies showing lowest prevalence in United States $(0.1 \%)^{8}$ and highest in Egypt ( 24.8\%). [9]Various other Indian studies indicate seroprevelance of HCV ranging from $0.4 \%$ 1.09\%. 9,10,13,14

Most of the above mentioned studies have shown increase prevalence of HBV as compared to HCV. The seroprevelance of HCV was highest $1.4 \%$ ) among all other TTD's in the present study which was comparable to the study done in Pakistan where HCV prevalence was $2.06 \% .{ }^{15}$

Majority of the sero-positive donors were between 18-35 years age group in the present study, which is alarming, considering the fact that this is the age during which a person is considered healthy and can give maximum number of blood donation. Few other studies also showed increase prevalence of TTI's in 18-35 years of age group. ${ }^{16,17}$

Dual infection was seen in $1.2 \%$ of the total TTI's in our study of which most common co-infection was HBV and HCV( 14 out of 23 ), which was similar to study done by Rodenas et al. ${ }^{17}$ Few other studies showed HIV to be the commonest co-infection associated with hepatitis infection. 1,18

The results from our study as well as various studies mentioned, showed the endemicity and the rising prevalence of both HBsAg and HCV in an apparently healthy population as compared to HIV. There is consequent risk of transmission of these viruses through blood/blood products, albeit unknowingly. So far, most of the published data worldwide is on HIV/AIDS and much is being done regarding its prevention and cure by various government organizations as well as World Health Organization.

Journal of Evolution of Medical and Dental Sciences/Volume1/Issue5/November-2012Page-877 
Despite various studies suggesting an increase in the hepatitis infection not much has been done for its prevention. The emphasis must be given to increase the knowledge and to change the attitude of the people. It was shown that the risk of HIV infection in SanFrancisco declined substantially, to about 0.2 per cent as a direct result of efforts to educate at risk individuals to avoid donation 14 .

RECOMMENDATIONS: Various measures like strict donor selection criteria, use of sensitive tests like Nucleic Acid Testing (NAT) and judicious use of blood and blood components have been taken to reduce the risk of TTI's per se. Pre-donation counseling, and self-exclusion of donors is a rare phenomenon seen in our set up. National agencies like National Aids Control Organization (NACO) and World Health Organization(WHO) should join hands along with various other voluntary organizations in doing community based study for Hepatitis to identify at risk and non- risk subjects. At risk subjects should be identified and preventive strategies should be made at the national level, as the risk factors might vary from one geographical area to another.

To achieve all this, strong political commitment, multi-sectorial engagement along with public awareness, educational and motivational programmes and mass immunization ( for Hepatitis B) should be done to substantially decrease the prevalence of hepatitis in an otherwise healthy population.

CONCLUSION: From our study it has been clear that prevalence of hepatitis is on rise especially infection with Hepatitis $C$ in healthy population without them being aware of it ("silent carriers") and carries the risk of transmitting infection albeit unknowingly.

\section{BIBLIOGRAPHY:}

1. Kaur G, Basu S, Kaur R, Kaur P, Garg S. Patterns of infections among blood donors in a tertiary care centre: A retrospective study. Natl Med J India $2010 ; 23: 147-9$

2. Kalepoto G.N., Bhally H.S., Khaliq G. Epidemiology of blood-borne viruses. A study of health blood donors in southern Pakistan. J. Pak. Med. Assoc 1996; 27: 703-6.

3. Karki S, Ghimire P, Tiwari BR, Maharjan A, Rajkarnikar M. Trends in hepatitis B and hepatitis C seroprevalence among Nepalese blood donors. Ind Jl Infec Dis 2008; 61: 324326.

4. Bhattacharya P, Chandra PK, Datta S, Banerjee A, Chakraborty S, Rajendran K, Basu SK, Bhattacharya SK, Chakravarty R. Significant increase in HBV, HCV, HIV and syphilis infections among blood donors in West Bengal, eastern India, 2004-2005. World Journal of Gastroenterology 200; $13: 3730-3733$.

5. Singh B, Kataria SP, Gupta R. Infectious markers in blood donors of East Delhi: Prevalence and trends. Indian J Pathol Microbiol 2004;47:477-479.

6. Karki S, Ghimire P, Tiwari BR, Maharjan A, Rajkarnikar M, Trends in hepatitis B and hepatitis $\mathrm{C}$ seroprevalence among Nepalese blood donors. Indian Journal of Infectious Diseases 2008; 61:324-326.

7. Bhawani Y, Rao PR, Sudhakar V. Seroprevalence of transfusion transmissible infections among blood donors in a tertiary care hospital of Andhra Pradesh. Biology and Medicine, $2010 ; 12: 45-48$ 
8. Dienstag J.L., Isselbacher K.J. Acute viral hepatitis In Braunwald E. Fauji A.S., Kasper D.I. et al. 15th ed. Harrison's principles and practice of internal medicine. New York McGraw Hill 2001: 1721-37.

9. Chandrasekaran S, Palaniappan N, Krishnan V, Mohan G, Chandrasekaran N: Relative prevalence of hepatitis B viral markers and hepatitis C virus antibodies (antiHCV) in Madurai, South India. Indian Journal of Medical Sciences 2000;547:270-273.

10. Srikrishna A, Sitalakshmi S, Damodar P: How safe are our safe donors?. Indian Journal of Pathology and Microbiology, 1999;424:411-416.

11. Choudhury N, Ramesh V, Saraswat S, Naik S: Effectiveness of mandatory transmissible diseases screening in Indian blood donors. Indian Journal of Medical Research, 1995;101:229-232.

12. WHO hepatitis C. WHO fact sheet No164, October 2000b.Available from URL.http:/www.who.int/mediacentre/factsheets/fs164/en/print.htm. [Cited on 2007 May 14]

13. Sharma RR, Cheema R, Vajpayee M, Rao U, Kumar S, Marwaha N, Agnihotri SK: Prevalence of markers of transfusion transmissible diseases in voluntary and replacement blood donors. The National Medical Journal of India, 2004;171:19-21.

14. Gupta N, Kumar V, Kaur A: Seroprevalence of HIV, HBV, HCV and syphilis in voluntary blood donors. Ind Jl of Med Sci, 2004;58:255-257.

15. Nazar H, Nadia N, Shazia A, Zulfiqar, Farhat A. Prevalenc of hepatitis B and C in blood donors in Karachi. Biomedica 2008;24:116-117

16. Shrestha AC, Ghimre P, Tiwari BR, RajKarnikar M. Transfusion- Transmissible infections among blood donors in Kathmandu, Nepal. J Infect Dev Ctries 2009;3:794-797

17. Rodenas JG, Bacasen LC, Que ER. The prevalence of HBsAg (+) anti $\mathrm{HCV}(+)$ among healthy blood donors at East Avenue Medical Centre, Quezon City. Phil J Gastroenterol 2006;2:64-70

18. Kapur S, Mittal A. Incidence of HIV infection and its predictors in blood donors in Delhi. Indian J Med Res 1998;108:45-50.

Table 1 showing trend of TTI reactivity among males and females

\begin{tabular}{|l|l|l|}
\hline TTD Reactive( $\mathbf{n = 1 7 5 5 )}$ & Male & Female \\
\hline HCV & 879 & 18 \\
\hline HBV & 611 & 15 \\
\hline HIV 1\&2 & 142 & 1 \\
\hline VDRL & 73 & 2 \\
\hline MP & 14 & - \\
\hline Total & $\mathbf{1 7 1 9}$ & $\mathbf{3 6}$ \\
\hline
\end{tabular}

Table 2 showing dual reactivity among Blood Donors

\begin{tabular}{|l|l|}
\hline TTD.s( Dual reactivity) $\mathbf{n = 2 3}$ & Number \\
\hline HBV+ HCV & 14 \\
\hline HIV1\&2 + HCV & 06 \\
\hline HBV+ HIV1\&2 & 01 \\
\hline HBV + VDRL & 01 \\
\hline HCV+ VDRL & 01 \\
\hline
\end{tabular}

Journal of Evolution of Medical and Dental Sciences/Volume1/Issue5/November-2012Page-879 
Fig 1 shows distribution of Transfusion Transmitted diseases ( $n=1755)$ among blood donors

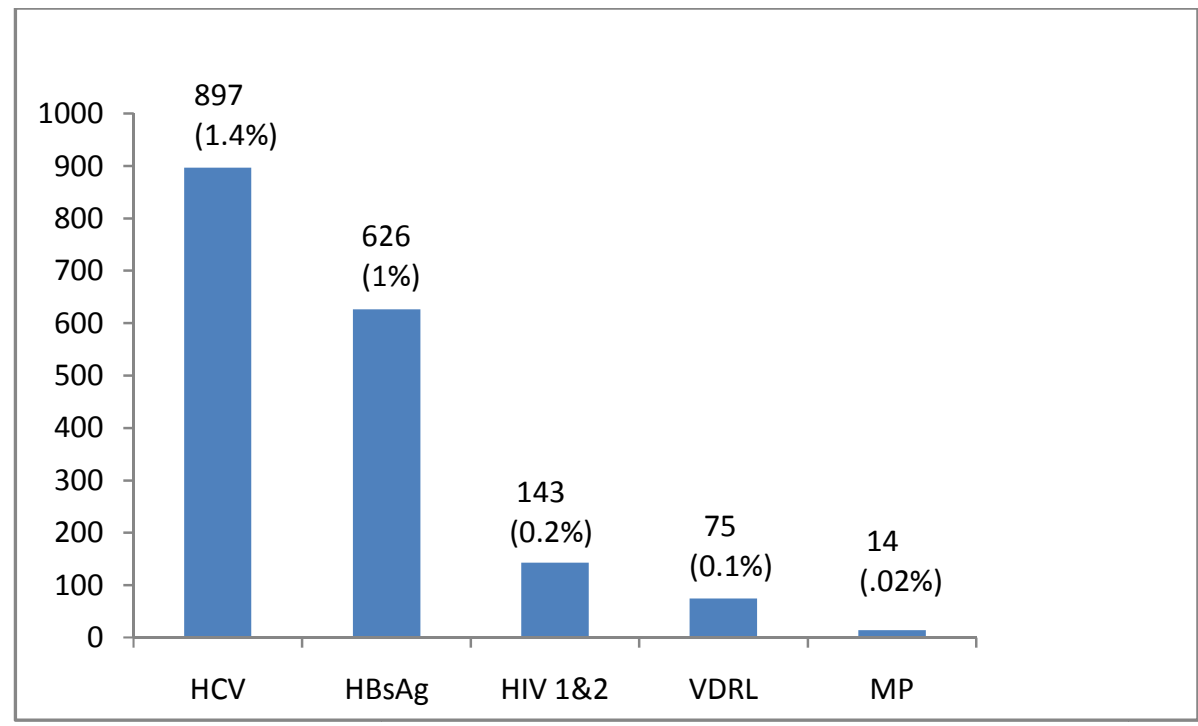

Fig 2 showing age groups among various TTD reactive blood donors

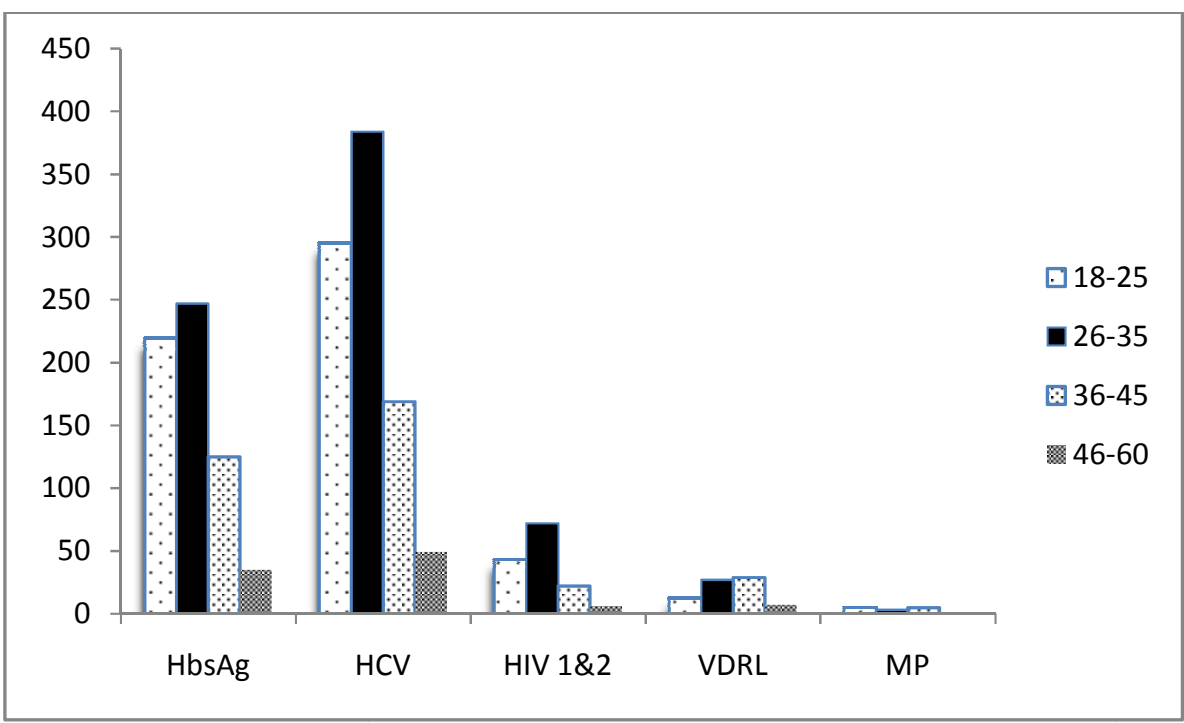


Fig 3 showing prevalence of Hepatitis among blood donors

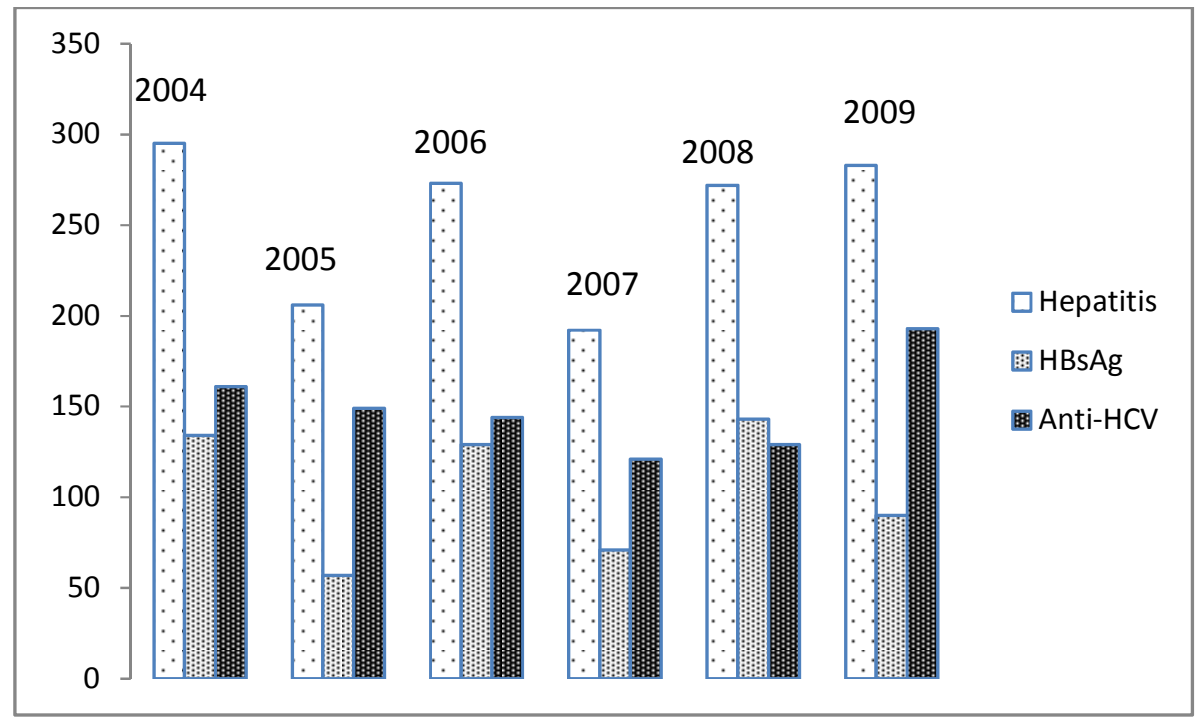

Journal of Evolution of Medical and Dental Sciences/Volume1/Issue5/November-2012Page-881 